

\title{
THE LINKS BETWEEN CULTURE AND OHS: A LITERATURE REVIEW
}

\author{
Felicity Lamm and Edwina Pio
}

\author{
School of Business, \\ Auckland University of Technology
}

There is growing recognition that as workplaces become more culturally and ethnically diverse, OHS prevention and investigation must be seen within the context of a cross-cultural milieu. In particular, investigations into workplace fatalities, injuries and illnesses have indicated that many of the root causes are the lack of communication or the inability to make sense of the communication and where cultural diversity factors are at play. The focus of this paper, therefore, is: "What evidence is there in the literature on the links between culture and OHS?" In particular, this paper identifies the key debates, strengths and weaknesses of the research on the topic. Finally it is argued that more attention is required on the subject of cultural diversity and its impact on OHS and employment relations in general which has implications for power relations between different groups/individuals in the workplace. Hence, further exploration of the significance of cultural diversity and communication and OHS is encouraged.

\section{Introduction}

As a way of stimulating debate and broadening the discourse on occupational health and safety (OHS) within the New Zealand context, the Department of Labour (DoL) has funded a number of studies, including a review of the extant literature on culture diversity, communication and workplace health and safety, part of which is reported in this paper. This literature review was undertaken by a team of researchers from the New Zealand Institute of Work and Labour Market Studies, located at AUT University on behalf of and in collaboration with the DoL. In particular, the purpose of the literature review was to explore the nexus between workplace culture, OHS and productivity and to provide the basis for further empirical research.

This paper reports on risk and risk management and the links with culture. More precisely, a summary of the criteria applied to the literature review and an overview of the different ways the topic has been viewed will be discussed.

Key themes and debates as well as gaps identified in the literature will be also highlighted. However, undertaking a literature review specific to this topic was not an easy task, as the literature was difficult to locate, being dispersed amongst multiple discourses. Such discourse included industrial psychology, occupational health and safety, risk management, cultural studies, sociology, and employment relations. This exposure to a wider body of knowledge encouraged the research team to question the basic premises which underlie the general area under investigation.

Further, endeavouring to find points of connection between the concepts of risk management, risk-taking behaviour, and culture is complex (Lawton \& Parker,
1998: Nicholson et al, 2005). Nonetheless there is a view that when implementing OHS risk management it is important to identify factors that influence the decisionmaking process, such as the propensity for risk-taking behaviour. Employers' and employees' perception of risk and associated norms and practices can all play a role in the health and safety decisions and strategies (Powell, 2007). There is general agreement that within organisations there are three major influences operating at the same time on the behaviour of employers and employees: culture (including communication), processes and structure (see Figure 1). These influences are dynamically interrelated, and they influence and are influenced by one another. Together they provide the milieu in which safety-related behaviour takes place and risk is perceived (Guldenmund, 2000) as depicted by Swuste's (2008) model and used to provide a framework for the paper.

Figure 1: Major Influences on Behaviour

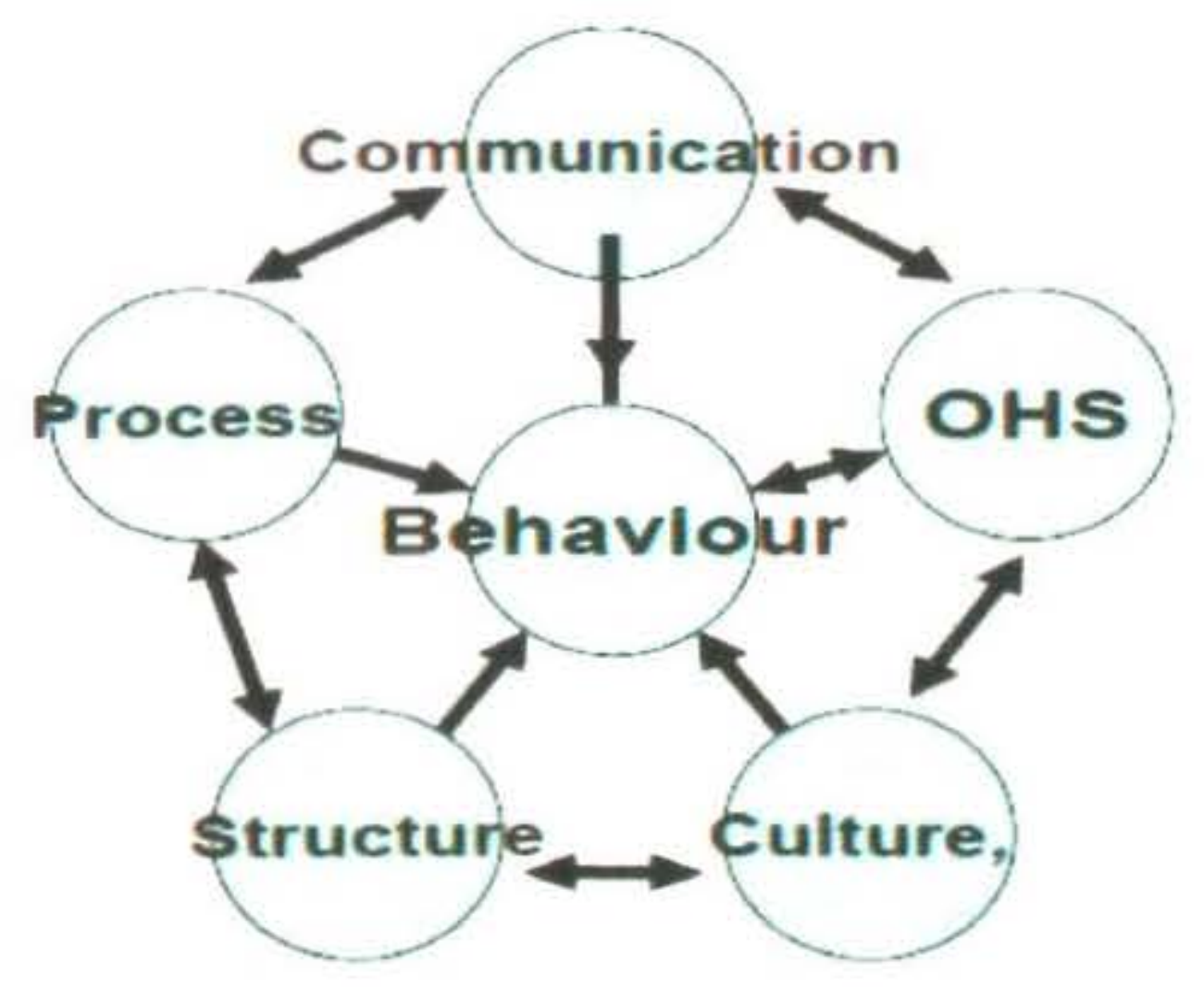

Source: Swuste, 2008:444 


\section{Behaviour}

At the centre of most studies on risk and risk management, particularly those located within the psychology discipline, is the behaviour of individual actors and in particular their safety and risk-taking behaviour and/or "sensation seeking" behaviour. The so-called sensation seeking behaviour or "risk-taking behaviour" of employees is often cited as an important micro level factor in the occurrence of accidents and injuries (refer to Zuckerman, 1984 and Zuckerman, et al 1993; Harrison et al, 2004; Glendon et al., 2006).

There is an underlying assumption underpinning risktaking behaviour that everyone has a propensity to take risks and that this propensity differs from one individual to another depending on a number of factors, such as perception of the nature of the costs and benefits of taking the risk (Adams 1995).

There is still a lack of consensus, regarding not only the definition but also measurement of the propensity to take risks. For example, in a review of the literature on the relationship between accident liability and individual differences, focusing specifically on accidents at work between 1970 and 1997, Lawton and Parker (1998: 657) note that there are significant methodological problems with accident liability research in that most of the studies are retrospective. In order to overcome this deficit, Nicholson et al (2005) argue that for their study it was necessary to develop a new scale assessing overall risk propensity in terms of reported frequency of risk behaviours in six domains: recreation, health, career, finance, safety and social.

Gonçalves et al (2008:999) also argue that safe behaviour and unsafe behaviour have different determinants. although it is easier to predict unsafe behaviour than safe behaviour. Their cross-sectional study based on selfreported data, shows that experience of work accidents appear to be a good predictor of unsafe behaviour, and that this relationship is mediated by external attributions (i.e. the lack of inspection from the governmental authorities). However, the reverse pattern was not found for safe behaviour. These authors state that work accident experience performs a central role affecting workers' perceptions and behaviours, suggesting that organisational learning from accidents can be important at the individual level, especially if the attribution pattern is considered. They conclude that their study enhances the importance of focusing on the attribution of accidents in the workplace after an accident, and it suggests that unsafe and safe behaviours should be considered as somewhat different realities. While these authors acknowledge that communication and training are important factors in safety culture, the link between unsafe behaviour and cultural attributes was unclear.

Though risk behaviour has been studied intensely, there is less research on the perception of risk (i.e., risk attitudes, such as, risk propensity and risk aversion). As Powell (2007:15) states, investigating risk perception is an essential component in the workplace injury and illness prevention yet individuals and groups view risks in different ways. These differential perceptions may reflect differing social norms, experience and skill levels, and individual differences.

In a structured review of qualitative research on perceived risk focusing upon methodological issues, Hawkes and Rowe (2008:638) suggest that this discourse suffers from an incomplete coverage of the 'risk perception universe', typified by a focus on atypical hazards and study samples. Most of studies rely on one method of data collection; that is face-to-face, semi-structured interviews and therefore will have an inherent basis. They argue that in order to overcome this bias, more than one research technique needs to be utilised. They observe that most studies have effectively used convenience samples, suggesting a lack of awareness by researchers of the importance of certain demographic/socio-economic factors for risk perception.

Moreover Rohrmann (2004:1) argues that it is widely assumed that people differ considerably in their attitude towards risks, ranging from cautiousness to risk-seeking and even pleasure in risk-taking. However, there was no convincing evidence that this dimension is a general trait (rather than a state, or a domain-specific attitude, e.g., distinct for physical, financial, or social risks people may encounter). Furthermore, Rohrmann found that no established measurement tools existed. To this end, he proposed the conceptualization of risk attitudes by applying several new instruments - namely, Risk Orientations Questionnaire, Risk Propensity Questionnaire, Risk Scenarios Questionnaire, and Risk Motivations Questionnaire.

\section{Communication}

Communication research is ideally suited to study safety in organisations, as communication failure is often a factor in many workplace injuries and fatalities, and includes but is not limited to, the availability and effectiveness of safety information and safety campaigns (Real, 2008: 339). As a means of preventing accidents, injuries and illnesses, communication is an essential ingredient in to warn and inform about hazards (McComas, 2006; Boholm, 2008). Since the mid-1980s however, communication research within the context of OHS has undergone significant growth in defining the factors that determine whether a communication will or will not be effective. Most of this attention has been directed at warning labels accompanying consumer products, warning signs in various environments, warning messages delivered via print and electronic media, and various other speech and pictorial warnings (DeJoy and Wogalterb, 1993). A number of researchers have also noted that safety climate can influence safety-related communication (e.g. DeJoy \& Wogalterb, 1993; Hoffman \& Stetzer, 1998; Cooper \& Phillips, 2004). Cheyne, et al (1998:256) define safety climate as "...a temporal state measure of culture, which is reflected in the shared perceptions of the organization at a discrete point in time".

While there has been an increase in the number of studies on communicating risk within the workplace, there are 
still few, if any, studies that examine the links between risk, communication and cross-cultural communication. Moreover, Real (2008: 354) argues for more research into the role of safety culture and climate, trust, and identity in shaping safety behavior and communicative activity. He also suggests a stream of research entailing examining how discourse and other discursive practices shape safety in the workplace (see Zoller, 2003; Thackaberry, 2004). Finally, he states that while much risk communication research is formulated at the formal level (e.g., Seeger, et al 2003), future research could examine the extent to which organizations could potentially utilize the concepts of risk communication within the culturally diverse organizations in order to prevent workplace injury and illnesses (Real, 2008:354).

\section{Culture}

Launched by Mary Douglas (1978) and Douglas and Wildavsky (1982), cultural theory has also been important in the discussion on risk perception and risk interpretations (Dake, 1991; Wildavsky and Dake, 1990). Further the perceived risk is also closely tied to cultural adherence and social learning (Oltedal, et al., 2004:5). Depending on whether one is socially participating and which groups one belongs to, one will focus on different kinds of risks (Simard and Marchand, 1997). According to Wildavsky and Dake (1990: 42) the cultural theory of risk can "predict and explain what kind of people will perceive which potential hazards to be how dangerous". However, the ability to explain and predict risk behaviour through cultural theory has its critics. As Oltedal et al (2004:33) argue, "... it may simply be due to the power of persuasion, that the supporters of cultural theory have been good advocates and managed to promote their views in a convincing way."

Within the discipline of OHS, "culture" typically refers to "safety culture" and is viewed as a product of individual and group values, attitudes, perceptions, competencies, and patterns of behaviour that determine the commitment to, and the style and proficiency of, an organization's health and safety. Since the 1980 's there has been a great deal of research conducted on safety culture. However, the concept still remains largely ill-defined and a tendency for safety culture to be expressed in terms of attitudes or behaviour (See (Guldenmund (2000), Cooper, (2000), and Reason (2000) for a more detailed examination of the concepts of "culture", "safety" and "safety cultural").

Glendon et al. (2006: 367) highlight that when defining safety culture, the premise of some researchers is to focus on attitudes, where others emphasize safety culture being expressed through their behaviour and work activities, (i.e. Guldenmund, 2000). In other words, the safety culture of an organisation acts as a guide as to how employees will behave in the workplace. Their behaviour will also be influenced or determined by what behaviours are rewarded and acceptable within the workplace. For example, Clarke $(2006$, p. 278$)$ states that the safety culture is not only observed within the "general state of the premises and conditions of the machinery but in the attitudes and behaviours of the employees towards safety".

Within the safety culture literature there is also a bias towards quantitative methodologies and towards the discipline of psychology. In Jackson's (2007:4) systematic review of the literature on workplace safety culture, he notes that all the studies included in the review only used quantitative data and the researchers developed their own scales to measure safety cultures and climates, although many borrowing heavily from Zohar's (2003) 40 -item questionnaire scale.

Moreover, in the Work \& Stress 1998 special issue on safety culture, Pigeon (1998: 204) comments that psychological attempts to 'measure' safety culture tend to focus upon individual attitudes and behaviour, while engineering approaches look more at the development of formal reliability and systems modelling with only limited attention to some of the complexities of the human issues involved. He adds that "[n]either of these two approaches, while highly valuable in and of themselves fully address the anthropological origins of the culture concept, its symbolic aspects, or the wider ergonomic, sociological or political issues that bear upon the generation of accidents in organizations. Mearns and Yule (2008: 3 ) also caution that there is an assumption in the safety literature that the workforce's safe or unsafe behaviour is a function of the organisation's prevailing safety culture, yet the direction of causality is not well established in this relationship.

Although each concept contributes to the many layers of the organisation of work, the connections and distinctions between safety culture, culture, cross-culture and cultural diversity are less clear. Given the increasing diversity of workplaces in terms of culture, gender and ethnicity (Konrad, et al, 2006; Pio, 2007, 2008) as well as the many different forms of work (permanent, part-time, casual, etc), it is not surprising that there have been attempts more recently to understand the impact of cross-culture on safety culture.

One of the dominant frameworks for analyzing crossculture and safety has been to distinguish between collectivism and individualism. It has been argued that the dominant cultural outlook in the West is individualism in which the self is the primary social reality (Christopher et al 2000: 3). In contrast to individualism, collectivism "...prioritizes the group over the individual and sees the group as more than the sum of its individual members. For collectivists, one's "psychological self" reaches out to incorporate others ... [in which] ... identity derives not from individual attributes but rather from the social system (Christopher, et al 2000: 4). By recognising that the world can be divided into dichotomous collectivism versus individualism groups, proponents argue that we are better able to understand how health and safety interventions will generally impact on a given workforce (refer to Hofstede, 1991; Carroll 1998; Brewer and Chen, 2007)

However, Tan (2002: 815) argues that a major problem with cross-cultural research is that "culture" is often equated with a particular country even though the two 
concepts are not necessarily the same. This has meant that national differences found in the characteristics of organizations or their members have been interpreted as cultural differences. Indeed, most cross-cultural studies present more complex paradigms than the collectivism versus individualism split in which the three dominant ones are: convergence theory; divergence theory; and crossvergence theory (see Tan (2002) for a more detailed discussion). The convergence theorists claim that as countries become industrialized, the business environments in terms of technology and contextual variables (such as complexity, formalization, and centralization) are homogenized. The divergence theorists, however, propose that cultures are deeply rooted within individuals and groups and as such will be retained regardless of economic ideology. Finally, the crossvergence theorists assert that the integration of cultural and economic ideological influences will result in a unique value system different from in many respects the original cultures.

Based on a review of published literature on crosscultural differences in attitudes, perceptions and beliefs regarding safety, Mearns and Yule (2008: forthcoming) conclude that there are no consistent predictors of risk taking behaviour and safety performance across cultures. They highlight emerging research in which there appears to be an intersection between national and organisational environmental/cultural factors (see for example Spangenbergen et al., 2003, (Mearns and Yule 2008, forthcoming).

\section{Process}

In the context of risk management, the role of process is important particularly when discussing the process of managing risk, modifying behaviour and standards that identify a particular process, or series of steps, to be followed in the pursuit of safety.

Efforts to change the behaviour of an individual to operate safely have been translated into a process of behaviour modification. The popularity of behaviour safety programmes amongst employers has created and sustained an entire industry. Behaviour modification programmes, however, have been severely criticised because in general they place the prime responsibility for reducing harm on the individual employee, thus abdicating the employer's duty of care (Lamm, et al 2007). Another major drawback of behavioural modification programs is that they run the risk of assuming that unsafe behaviour is the only cause of accidents worth focusing on (Hopkins 2006: 594). Moreover, such approaches fail to recognise or diminish the importance of the sociology of work, the complexities of employment relationships and the influence of external economic, political and legal factors (Hopkins, 2006: 594). Specht et al (2006: 530) suggest that instead of concentrating just on the individual employee, a more productive approach is to link risk behaviour, risk management, and culture under an umbrella concept of "human risk management system".

Thus a more advanced thinking on the process of risk management is to adopt a multi-pronged approach that includes interweaving not only the elements of risk management (communication, training, etc), but also incorporating quality systems and worker participation schemes as well as incorporating OHS standards (Buff and Gunningham, 2003:13). In turn, this complex paradigm will provide businesses with regulatory and financial incentives to contribute to the better management of health and safety, not only within their organisations, but also to organisations lower down the supply chain (Landeweerd et al 1990; Weil and Mallo, 2007; Lamm et al 2007). Research also indicates that managing risk, and complying with health and safety rules, is reliant on a larger cultural set of safety practices that should include not only employees, but also senior managers (Simard and Marchand, 1997; Lamm and Walters, 2004).

Given that it is the behaviour of management that is most critical in creating a culture of safety in any organisation, behavioural safety observations are likely to have their greatest impact if directed upwards at managers (See Smallman and John, 2001 and Swuste, 2008). Considerable thought, however, needs to be given to how this can be best achieved, as Hopkins, (2006: 594) notes:

\begin{abstract}
"...the evidence is that safe behaviour programs do not work when the workforce mistrusts its management and believes that this is just another way to hold workers responsible...Perhaps the best way to introduce safe behaviour programs is to start with upward appraisals of management behaviour. Only when progress is made in these areas are safe behaviour programs aimed at front line workers likely to achieve their full potential."
\end{abstract}

\section{Structure}

The relationship between the culture, process, behaviour and organisational structure is well established, (see for example Child, 1972). While organisational structure, together with human and technological factors, has been viewed for many years as an influential factor in improving safety, understanding accidents better and changing behaviour, marrying organisational theories with safety, accident and behaviour research is largely undeveloped.

Le Coze (2005) states that merging complexity, organisational theories and methodologies as well as indepth accident investigation for the purpose of improving workplace health and safety are essential in understanding how to improve the working environment for a culturally diverse workforce. In an attempt to address this oversight, Le Coze (2005) has classified the rationales of organisational theory and safety, accident and behaviour research. He The different perspectives range from Hale et al.'s (1997) structural safety management systems viewed through the introduction of the human resources, political and symbolic frames to the systematic Occupational Health and Safety Management (Frick and Wren, 2000; Bluff and Gunningham, 2003). Glendon, et al (2006) proposed a thematic matrix linking risk 
contexts, human factors and formal coping arrangements in order to understand disasters.

Recognising that knitting organisational theories with safety, accident and behaviour research is useful, Mullen (2004: 276) comments that few researchers have examined whether individuals are conscious of the risks associated with their jobs and whether they understand the implications of performing the work unsafely. She also argues that it is important to consider other possible organisational and social factors that precede the actual accident/injury and indirectly influence safety behaviour. Vaughan (2002) also states that organisational deviance is the result of a combination of the environment of the organisation, of the organisational characteristics (structure, processes, and tasks) and of the cognitive practices of individuals within them (in a newinstitutional perspective).

Recently a more inclusive approach to systematically managing OHS - namely Occupational Health and Safety Management (OHSM)- has become prominent, focusing on the organisational structure, responsibilities, practices, procedures, processes and resources for implementing and maintaining OHSM (Buff and Gunningham, 2003: 13) which spans:

\begin{abstract}
"...the entire organisation by relating the organisation to its environment, setting the goals, developing comprehensive, strategic, and operational plans, designing the structure, and establishing control processes. In doing so, it encourages organisations to address OHS in a more proactive and holistic way. Moreover, because systematic OHSM involves identifying responsibility at each level of the organisation, including the top, it directly makes responsible and engages management and workers at different levels."
\end{abstract}

\section{Conclusions}

A number of the key themes require further investigation. First, there is still the preoccupation with the individual as the sole unit of analysis although a growing recognition that a socio-technical approach is a more useful approach. Second, as depicted in Glendon et al.'s (2006) work, there are distinct approaches for measuring and categorising risk, each with their own strengths and weaknesses. However, adopting a multidisciplinary approach overcomes a myopic and limited approach. Third, the nuanced differences between risk behaviour, risk behaviour and risk-taking behaviour still require more scrutiny. Finally, there is a universal plea for a more inclusive approach to measuring such nebulous concepts as risk management, risk-taking behaviour and culture in order to determine what is occurring within culturally diverse workplaces.

\section{References}

Adams, J. (1995). Risk. London: UCL Press.

Bohle, P. and Quinlan, M. (2000). Managing Occupational Health and Safety: A Multidisciplinary Approach. Sydney: Macmillan.

Boholm, A. (2008). New perspectives on risk communication: uncertainty in a complex society. Journal of Risk Research, 11(1): 1-3.

Brewer, M, and Chen Ya-Ru. 2007. Where (who) are collectives in collectivism? Toward conceptual clarification of individualism and collectivism. Psychological Review, 114 (1):133-51.

Bluff, E. and Gunningham, N. (2003), Principle, Process, Performance or What? New Approaches to OHS Standards Setting, National Research Centre for OHS Regulation, Working Paper 9, http://ohs.anu.edu.au/

Carroll, J. S. (1998). Safety culture as an ongoing process: Culture surveys as opportunities for enquiry and change. Work \& Stress 12(3): 272 284.

Cheyne, S.; Oliver, A. and Tomas, J. (1998). Modelling safety climate in the prediction of levels of safety activity. Work \& Stress 12(3): 255-271.

Child. J. (1972) Organizational Structure, Environment and Performance: the role of strategic choice. Sociology, 6: 1-22.

Christopher, S., Christopher, J., C., Dunnagan, T. (2000). Culture's Impact on Health Risk Appraisal Psychological Well-Being Questions. American Journal of Health Behavior, 24(5): 338-355.

Clarke, S. (2006). Safety Climate in an automobile manufacturing plant. Personnel Review 35(4): 413-430.

Cooper, M. (2000), 'Towards a Model of Safety Culture', Safety Science, 36: 111-136.

Cooper, M. and Phillips, R. (2004). Exploratory analysis of the safety climate and safety behavior relationship. Journal of Safety Research 35: 497512 .

Cox, S. and Flin, R. (1998). Safety culture. Work \& Stress $12(3): 187$ - 8.

Dake, K. (1991). Orienting Dispositions in the Perception of Risk: An Analysis of Contemporary Worldviews and Cultural Biases. Journal of CrossCultural Psychology 22: 61-82. 
DeJoy, D. M. and Wogalter, M. S. (1993). Warnings and risk communication. Safety Science, 16(5-6): 565-568.

Dingsdag, D. P. B., Herbert C.; Sheahan, Vaughn L. (2008). Understanding and defining OHS competency for construction site positions. Safety Science, 46: 619-633.

Dorman, P. (2000) The Economics of Safety, Health, and Well-being at Work: An Overview. International Labour Organisation.

Douglas, M. (1978). Cultural Bias. Occasional Paper No. 35, Royal Anthropological Institute of Great Britain and Ireland.

Frick $\mathbf{K}$ and Wren J. Reviewing OHSM at the Close of the 20th Century. In Systematic OHSM: perspectives on an international development, (edited) Elsevier, Oxford.

Glendon, A. I., Clarke, S.G., and Mckenna, E.F. (2006) Human Safety and Risk Management, (2nd ed), Taylor \& Francis, Boca Raton.

Goetzel, R.Z. and Ozminkowski, R.J. (2000), 'Health and Productivity Management - Emerging Opportunities for Health Promotion Professionals for the 21st Century." Critical Issues and Trends, American Journal of Health Promotion, 14(4): 215-217.

Gonçalves, S. M. P., S. A. da Silva, et al. (2008). The impact of work accidents experience on causal attributions and worker behaviour. Safety Science 46(6): 992-1001.

Guldenmund, F. W. (2000) The nature of safety culture: a review of theory and research. Safety Science 34(1-3): 215-257.

Hale, A. R. (2000). Culture's confusions. Safety Science, 34(1-3): 1-14

Hale, A.R., Heming, B.H.J., Carthey, J., Kirwan, B. (1997). Modelling of safety Management Systems. Safety Science 26, 121-140.

Harrison, J., Young, J., Butow, P., Salkeld, G. and Solomon M.J. (2004) Is it worth the risk? A systematic review of instruments that measure risk propensity for use in the health setting. Social Science \& Medicine, 60; 1385-1396.

Hawkes, G. and Rowe, G. (2008). A characterisation of the methodology of qualitative research on the nature of perceived risk: trends and omissions. Journal of Risk Research 11(5): 617 - 643.

Hoffman, D. and Stetzer, A. (1998). The role of safety climate and communication in accident interpretation. Academy of Management Journal, 41(6): 644-657.
Hofstede, G. (1991). Cultures and Organizations: Software of the mind. New York: McGraw-Hill.

Hopkins, A. (2006). What are we to make of safe behaviour programs? Safety Science_44: 583-597

Jackson, C.A. (2004). The evaluation of occupational health advice in primary health care (Contract Research Report No. 242). HSE Books, London.

Konrad, A.M., Prasad, P. and Pringle, J.K. (2006) Handbook of Workplace Diversity. Sage Publications, London.

Lamm, F. and Walters D. (2004) 'OHS in Small Organisations: Some Challenges and Ways Forward'. In Buff, L.; Gunningham, N. \& Johnston, R. (eds) OHS Regulations for the $21^{S T}$ Century. Federation Press, Sydney.

Lamm, F., Massey, C. \& Perry, M. (2007). Is there a link between Workplace Health and Safety and Firm Performance and Productivity? New Zealand Journal of Employment Relations 32(1).

Lawrie, M., Parker, P. and Hudson, P. (2006). "Investigating employee perceptions of a framework of safety culture maturity." Safety Science 44(3): 259-276.

Lawton, R. and Parker. D. (1998). Individual differences in accident liability: a review and integrative approach. Human Factors, 40(4)5(1): $655-682$

Le Coze, J-C. (2005). Are organisations too complex to be integrated in technical risk assessment and current safety auditing? Safety Science, 43: 613638.

Le Coze, J.-C. (2008).Disasters \& organisations: From lessons learnt to theorising. Safety Science 46(1): 132-149.

Massey, C., Lamm, F., and Perry, M., (2005) Workplace productivity: NZ Experience, Department of Labour, Wellington

Massey, C., Lamm, F. and Perry, M. (2007) Understanding the Link Between Workplace Health \& Safety \& Firm Performance \& Productivity, Department of Labour, Wellington.

Mayhew, C. and Quinlan, M. (1999). The effects of outsourcing on OHS: A comparative study of factory-based and outworkers in the garment industry. International Journal of Health Services, 29(1):83-107.

McComas, K.A. (2006). Defining Moments in Risk Communication Research: 1996-2005. Journal of Health Communication, 11:75-91, 2006 
Mearns, K. and Yule, S. (2008). The role of national culture in determining safety performance: Challenges for the global oil and gas industry. Safety Science forthcoming.

Mullen, J. (2004). Investigating Factors that Influence Individual Safety Behavior at Work. Journal of Safety Research_35: 275- 285.

Nicholson, N., Soane, E., Fenton-O'Creevy, M., and Willman, P. (2005) Personality and domainspecific risk taking. Journal of Risk Research, 8(2): 157-176

Oltedal, S., Moen, B-E., Klempe, H., and Rundmo, T. (2004). Explaining risk perception: An evaluation of cultural theory. Trondheim, Norway, Norwegian University of Science and Technology, Department of Psychology.

Pidgeon, N. (1998). Safety culture: Key theoretical issues. Work \& Stress 12(3): 202-216.

Pio, E. (2007). Diversity Management. In Gill, L. and Pio, E. (Eds.). Organisations \& Management. Pearson, Auckland.

Pio, E. (2008). SARI: Indian women at work in New Zealand. Wellington: Dunmore..

Powell, C. (2007) The Perception of Risk and Risk Taking Behavior: Implications for Incident Prevention Strategies. Wilderness \& Environmental Medicine, Health Module; 18(1): 10-15.

Rasmussen, E. and Lamm, F. (2002), An Introduction to New Zealand Employment Relations. ( $2^{\text {nd }}$ ed), Prentice Hall, Auckland.

Ray, P. Purswell, J., Bowen, D. (1993). Behavioral safety program: Creating a new corporate culture. International Journal of Industrial Ergonomics 12: 193-198.

Real, K. (2008). Information Seeking and Workplace Safety: A Field Application of the Risk Perception Attitude Framework. Journal of Applied Communication Research 36(3): 339-359.

Reason, J. (2000). Safety paradoxes and safety culture. Injury Control \& Safety Promotion, 7(1): 3-14.

Rasmussen, J. (1997). Risk Management in a Dynamic Society: A Modelling Problem. Safety Science, 27 :183-213.

Rohrmann, B. (2004) Risk Attitude Scales: Concepts and Questionnaires: Project Report. University of Melbourne, Melbourne, www.psych.unimelb.edu.au.
Seeger, M., Sellnow, T., and Ulmer, R. (2003) Communication and organizational crisis, Praeger, Westport, Con.

Shannon, V., M. (2004). How low can they go? Potential for reduction in work injury rates. Injury Prevention. 10: 292-295.

Simard, M. and Marchand, A. (1997) Workgroups' propensity to comply with safety rules: the influence of micro-macro organisational factors. Ergonomics, 40(2): 172-188.

Smallman, C. (1996) Challenging Orthodoxy in Risk Management. Safety Science 22(1-3): 245-262.

Smallman, C. and John, G. (2001). British Directors' Perspective on the Impact of Health and Safety on Corporate Performance. Safety Science, 38(3): 227-239.

Spangenbergen, S., Baarts, C., Dyreborg, J., Jensen, L., Kines, P., Mikkelsen, K.L., (2003). Factors contributing to the differences in work related injury rates between Danish and Swedish construction workers. Safety Science, 41: 517-530.

Specht, M., Chevreau, F. R. and Denis-Remis, C. (2006). Dedicating Management to Cultural Processes: Toward a Human Risk Management System. Journal of Risk Research 9(5): 525-542.

Swuste, P. (2008). "You Will Only See It, If You Understand It" or Occupational Risk Prevention from a Management Perspective. Human Factors and Ergonomics in Manufacturing 18(4): 438-453

Tan, B. (2002). Researching managerial values: a crosscultural comparison. Journal of Business Research 55(10): 815-821.

Thackaberry, J. A. (2004). Discursive opening' and closing in organizational self-study. Management Communication Quarterly, 17: 319-359.

Van Vuuren, W. (2000). Cultural influences on risks and risk management: six case studies. Safety Science 34(1-3): 31-45.

Vaughan, D. (2002) Signals and Interpretive Work: the role of culture in a theory of practical action. In In Karen A. Cerulo (ed.) Culture in Mind: Toward a Sociology of Culture and Cognition. Routledge, New York:

Weil, D. and Mallo, C. (2007) Regulating Labour Standards via Supply Chains. British Journal of Industrial Relations, 45(4): 791-814

Wildavsky A, and Dake K (1990) Theories of risk perception: who fears what and why? Daedalus 119: $41-60$. 
Zohar, D. (2003). Safety climate: conceptual and measurement issues. In Quick, J.C. \& Tetrick, L.E. (Ed.), Handbook of occupational health psychology. American Psychological Association, Washington, D.C.

Zoller, H. (2003) Working Out: Managerialism in Workplace Health Promotion. Management Communication Quarterly. 17(2): 171-205.

Zuckerman, M. (1984). Sensation seeking: A comparative approach to a human trait. Behavioral and Brain Sciences, 7: 413-471.

Zuckerman, M., Kuhlman, D.M. Jorieman, J. Teta, P and Kraft, M. (1993). A comparison of three structural models for personality: the big three, the big five and the alternative five. Journal of Personality and Social Psychology, 65: 757-768.

\section{Author}

Felicity Lamm

Associate Professor

School of Business - Management

Auckland University of Technology

Private Bag 92006

Auckland 1142

Felicity.Lamm@aut.ac.nz

Edwina Pio

Associate Professor

School of Business - Management

Auckland University of Technology

Private Bag 92006

Auckland 1142

Edwina.Pio@aut.ac.nz 